\title{
Research on Holographic Multidimensional Evaluation System of Suppliers in Pumped Storage Enterprises
}

\author{
Hongliang Wang ${ }^{1}$, Xiaoran Pang ${ }^{2,}$, Yeting Wang ${ }^{1}$, Yujian Zhang ${ }^{2}$, Xi Yin ${ }^{1}$, Tong Chen ${ }^{2}$ and Yang Yao ${ }^{2}$ \\ ${ }^{1}$ State Grid Xinyuan Holdings Limited Company, 100761 Beijing, China \\ ${ }^{2}$ Beijing Jiaotong University, 100044 Beijing, China
}

\begin{abstract}
Based on the actual background of a pumped storage company, this paper researches and builds the supplier holographic multidimensional evaluation system. By building supplier data mart, it realizes supplier data integration and visual management. By building supplier portrait system, it reflects the comprehensive performance of suppliers in different business scenarios. By applying the supplier multidimensional holographic evaluation system, from the life long perspective of supplier management, this paper realizes intelligent comparison of qualification performance verification data, bidding assistant management, real-time control of performance process, supplier recooperation assistant decision and so on, so as to assure the company's safe and stable operation.
\end{abstract}

\section{Introduction}

The digital and modern supplier management system is helpful to maintain the benign cooperative relationship between enterprises and suppliers. Pumped storage power station needs a large amount of investment and a long production cycle. Compared with general electric power enterprises, it plays an important role in the safe and stable operation of regional power grid. Under the background of State Grid promoting the deep application of modern intelligent supply chain, pumped storage enterprises are in urgent need of information transforma-tion in supplier management business.

In the process of supplier management informationization construction, pumped storage enterprises are prone to such defects as data unstructured, lack of historical data management, and poor data correlation between businesses. Only by giving full play to the digital value of supplier management can it serve the development of enterprises.

Many scholars have studied the hierarchical and classified management of suppliers, developed generally three classifications. One is to use big data technology to label and classify suppliers. Jingxiang Wang1 used Karajak model combined with analytic hierarchy process to classify and calculate index weights. Hongyuan Zhang2 established supplier credit evaluation model by using the XGBoost algorithm, and Wei Fan3 proposed three portrait models of supplier groups. Secondly, use unsupervised learning method to conduct classified research on suppliers. Shideng Wu4 established the index framework of enterprise risk credit evaluation by using cluster analysis. The third is to combine key factors to form a matrix or grid chart for classification. Liu Shuai5 proposed a classification standard based on the degree of interdependence between enterprises and suppliers.

Existing researches mostly focus on different methods of supplier classification, but there are few researches on the actual construction of supplier evaluation in enterprises. Based on existing research, this paper explores a more comprehensive solution of supplier management in pumped storage enterprises.

\section{Construction of supplier holographic multidimensional evaluation system}

When dealing with complex business situation, the traditional supplier management method has the problems of slow response speed and difficult to make a systematic assessment of the supplier's performance ability and quality risk. The supplier holographic multi-dimensional evaluation system proposed in this paper solves the problems of discrete, low coupling and non-sharing of supplier data among different systems of an enterprise, realizes the all-around digital perspective of suppliers, and helps enterprises to conduct more accurate and effective supplier management. The logical structure of the system is shown in Fig 1. 


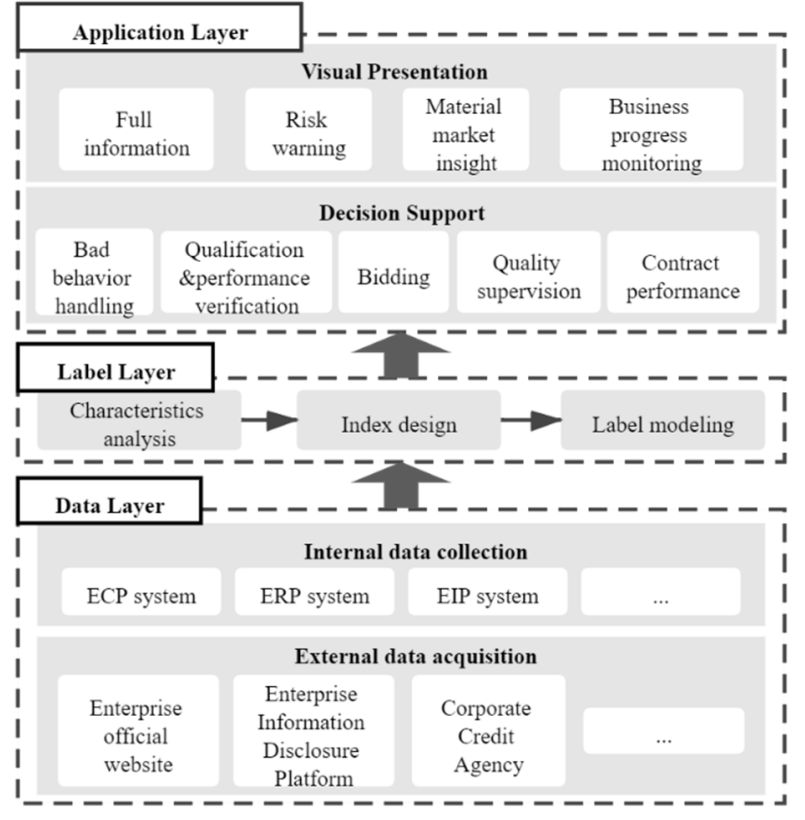

Fig.1 Logical structure diagram of supplier holographic multidimensional evaluation system

The data layer builds a supplier data mart by obtaining valuable data from the company's internal systems and file records, and obtaining external data services from external information disclosure platforms.

The indicator layer combines the business situation to sort out indicator dimensions and perform statistical calculations on the data with indicators, and uses supplier portrait technology to design labels for different indicators' calculation results.

The application layer visually presents the information collected by the data layer and the indicators calculated by the label layer, and intelligently assists the key links of supplier management through the results of indicator calculations.

\section{Construction of supplier data mart}

The construction of supplier data mart can meet the specific data needs of supplier management and make the access and analysis of data more flexible. The data acquisition methods of supplier data mart include internal data acquisition and external data collection.

\subsection{Internal data acquisition}

For suppliers that companies have cooperated with or are in cooperative relationship, the internal information system can be used to collect professional performance information.

In ECP, in addition to the basic information provided by suppliers, the engineering department and mechanical and electrical department evaluate the quality of provided equipment material, equipment installation and commissioning, construction quality, etc. of the supplier to form the professional evaluation score of the supplier's performance. ERP records the information of the core businesses of supplier management, covering the data of various professional departments and local power stations. The historical performance data of suppliers is accumulated in EIP, which can realize the structured storage of supplier credit, qualification and quality supervision information.

\subsection{External data collection}

For suppliers who have not cooperated with the enter-prise, the external system data is the necessary data source of the supplier data mart.

Through the enterprise information disclosure platform, basic information such as qualification certificate of suppliers can be collected. In addition, through the API service of enterprise credit investigation agency, real-time panoramic data and risk information of suppliers can be obtained, which can provide data support for the qualification and performance verification of bidding suppliers without cooperation basis.

\subsection{Data mart architecture}

Pumped storage enterprise has a large need of business data, it can build a subordinate data mart from the enterprise data warehouse for the supplier management business module, which can build the data basis for the supplier holographic multidimensional evaluation system. The logical structure of the supplier management theme data mart is shown in Fig 2.

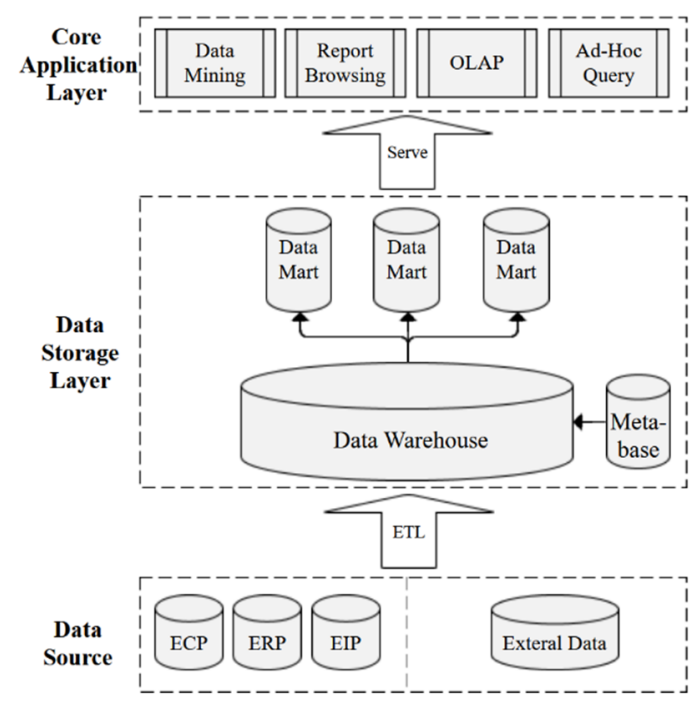

Fig.2 Logical structure diagram of supplier management theme data mart

\section{Construction of supplier portrait system}

\subsection{Construction of supplier portrait}

In this paper, user portrait is used as the portrait of enterprise suppliers. The core of supplier portrait is to label the supplier. Based on the static attributes and dynamic attributes of the supplier, the data is analyzed and processed by data mining technology to abstract the full 
feature of the supplier. The data state transformation steps of supplier portrait system are shown in Fig 3.

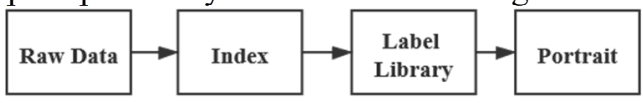

Fig.3 Data state transformation steps of supplier portrait

This paper establishes evaluation indicators based on the data mart, forms a supplier tag library, and builds a supplier profile. With the improvement of the portrait system and the increase of data, the calculation accuracy of labels should be iteratively optimized. The supplier portrait system's architecture is shown in Fig 4.

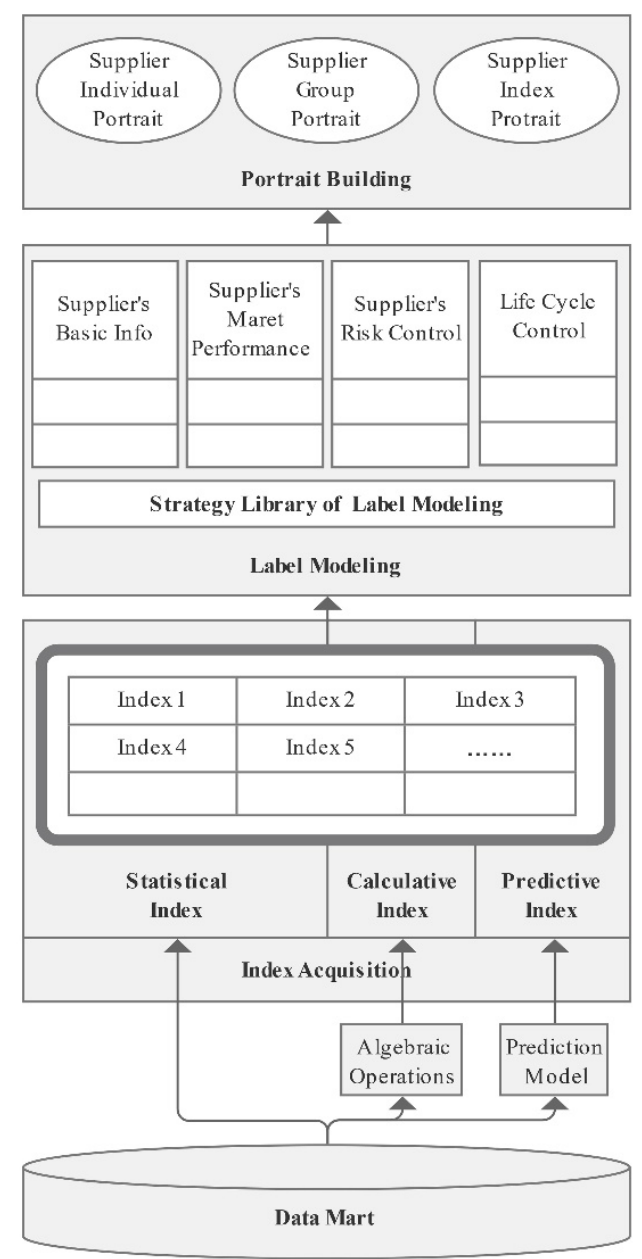

Fig.4 Architecture of supplier portrait system

\subsection{Label system design}

\subsubsection{Acquisition of indicators}

The acquisition of indicators refers to the supplier evaluation index model established after data acquisition. According to the actual business needs of supplier information of pumped storage enterprises in production practice, this paper selects several data fields, further calculates some fields, and comprehensively establishes the three-level index system, which is shown in Table1.
Table1. Supplier Indicators

\begin{tabular}{|c|c|c|}
\hline level 1 index & level 2 index & level 3 index \\
\hline \multirow{9}{*}{$\begin{array}{l}\text { Supplier } \\
\text { basic } \\
\text { information }\end{array}$} & \multirow{2}{*}{$\begin{array}{l}\text { Business } \\
\text { information }\end{array}$} & Business license information \\
\hline & & Qualification certificate information \\
\hline & \multirow{3}{*}{$\begin{array}{l}\text { Financial } \\
\text { information }\end{array}$} & Audit report \\
\hline & & Annual reports \\
\hline & & Equity structure \\
\hline & \multirow{3}{*}{$\begin{array}{l}\text { Key person } \\
\text { information }\end{array}$} & Legal representative information \\
\hline & & Personnel qualification certificate \\
\hline & & Other key person information \\
\hline & $\begin{array}{l}\text { Safety and } \\
\text { quality } \\
\text { condition }\end{array}$ & $\begin{array}{l}\text { Major safety and quality accidents } \\
\text { occurred within three years }\end{array}$ \\
\hline \multirow{13}{*}{$\begin{array}{l}\text { Supplier } \\
\text { market } \\
\text { performance }\end{array}$} & \multirow{4}{*}{$\begin{array}{l}\text { Operating } \\
\text { condition }\end{array}$} & Profit trends \\
\hline & & Market share \\
\hline & & Recent three-year performance \\
\hline & & $\begin{array}{l}\text { Competitiveness index of pumped } \\
\text { storage industry }\end{array}$ \\
\hline & \multirow{3}{*}{$\begin{array}{l}\text { Historical } \\
\text { cooperation } \\
\text { record }\end{array}$} & Historical contract information* \\
\hline & & Historical performance* \\
\hline & & Performance ratio \\
\hline & \multirow{6}{*}{$\begin{array}{l}\text { Industry } \\
\text { overall } \\
\text { profile }\end{array}$} & Number of suppliers \\
\hline & & Supplier scale distribution \\
\hline & & Regional supplier distribution \\
\hline & & Industry relevance \\
\hline & & Industry concentration \\
\hline & & Industry profit trend \\
\hline \multirow{11}{*}{$\begin{array}{l}\text { Supplier risk } \\
\text { control }\end{array}$} & \multirow{2}{*}{ Credit report } & Corporate credit report \\
\hline & & Enterprise credit information \\
\hline & \multirow{3}{*}{ Legal risk } & $\begin{array}{l}\text { Legal litigation, filing and court } \\
\text { information }\end{array}$ \\
\hline & & $\begin{array}{l}\text { Information of the executor and the } \\
\text { discreditor }\end{array}$ \\
\hline & & Consumption restriction order \\
\hline & \multirow{3}{*}{ Business risk } & $\begin{array}{l}\text { Administrative punishment } \\
\text { information }\end{array}$ \\
\hline & & Taxpaying outlier information \\
\hline & & Business anomaly information \\
\hline & \multirow{3}{*}{$\begin{array}{l}\text { Contract } \\
\text { performance } \\
\text { risk }\end{array}$} & Historical quality of service* \\
\hline & & $\begin{array}{l}\text { Historical production, operation and } \\
\text { supply* }\end{array}$ \\
\hline & & $\begin{array}{l}\text { Historical quality problems analysis } \\
\text { of equipment operation* }\end{array}$ \\
\hline \multirow{14}{*}{$\begin{array}{l}\text { Life-cycle } \\
\text { control }\end{array}$} & \multirow{3}{*}{$\begin{array}{l}\text { Result of } \\
\text { bidding and } \\
\text { procurement }\end{array}$} & History of bids \\
\hline & & Historical wining-bid conditions \\
\hline & & History of abandoned bid \\
\hline & \multirow{3}{*}{$\begin{array}{l}\text { Quality } \\
\text { monitoring } \\
\text { record }\end{array}$} & Supervision situation \\
\hline & & Sampling situation \\
\hline & & Life cycle quality service information \\
\hline & \multirow{5}{*}{$\begin{array}{l}\text { Results of } \\
\text { professional } \\
\text { performance } \\
\text { evaluation }\end{array}$} & $\begin{array}{l}\text { Qualification and capability } \\
\text { evaluation }\end{array}$ \\
\hline & & Production supply evaluation \\
\hline & & Installation service evaluation \\
\hline & & Operational quality evaluation \\
\hline & & Cost evaluation \\
\hline & \multirow{3}{*}{$\begin{array}{l}\text { Record of } \\
\text { bad behavior }\end{array}$} & Recording of bad behavior \\
\hline & & Bad behavior handling situation \\
\hline & & Correction of bad behavior \\
\hline
\end{tabular}

* all local power stations

\subsubsection{Label modelling}

Tag modelling builds the algorithm models between indicators and supplier performance and potential risks based on the indicator system. Indicators are further processed to get labels, aiming at providing easyunderstanding supplier performance description and assisting management decision for management departments. Amounts of labels constitute a label library to describe the characteristics of suppliers, and the 
accuracy of labels will be improved with the continuous iteration of data.

\subsubsection{Construction of portrait}

After label modelling, the label library can be used to realize supplier portrait and conduct comprehensive analysis on suppliers in three dimensions, as follows.

1) Supplier individual portrait. It displays the basic information, market performance, risk situation and performance of a single supplier in the form of radar chart to show the performance of a single supplier in different aspects.

2) Supplier group portrait. It demonstrates the performance of different suppliers provided same material, and make horizontal comparisons in various indicators. It can also give weight to different labels according to the special properties of material, calculate the scores of each supplier and make comparison.

3) Supplier indicator portrait. It shows the performance differences among different indicators in the process of supplier management. It averages and standardizes all supplier scores for different indicators, then make comparison between them. Through the indicator portrait, it can be found that the common weak link within all the suppliers, which is conducive to raise the enterprise's attention to a certain indicator and implement the reform.

In practice, the enterprise can utilize the supplier portrait label library to extract the holographic characteristics of supplier and develop visual interface. Through the bar chart, pie chart, radar map chart, etc. to portrait supplier performance as a result. This sort of supplier information presentation method solves the problems in traditional supplier management, such as low real-time degree, lack of intelligence and weakly personalized. And it can better assist enterprises in material supply chain management.

\section{Application of supplier holographic multidimensional evaluation system}

Pumped storage enterprise suppliers cooperation process has periodical characteristic. This paper divide it into probation, formation, stationary and re-cooperation deciding periods, the corresponding actual business in pumped storage enterprise is supplier qualification probation, bidding, contract signing and performing, and cooperation continuing or elimination four core processes, as shown in figure 5.

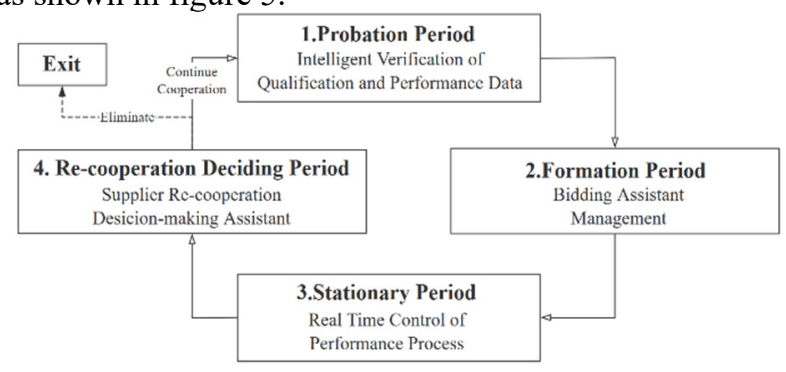

Fig.5 Supplier life cycle of pumped storage enterprises
In probation period, the supplier's holographic multidimensional evaluation system can provide support for supplier qualification performance verification, and establish targeted verification strategies for common problems based on supplier historical data.

In formation period, the material management department can utilize the system to carry out risk predictions on supplier credit, justice, and operation, so as to prevent untrustworthy suppliers from winning bids.

In stationary period, the company can predict the supplier's supply risk and quality risk based on the supplier's current and historical performance data, equipment operation problems, etc., and get early warning of possible breaches of contract. The quality supervision department can grasp the trend of changes in the incidence of similar material quality defects and implement differentiated manufacturing supervision and sampling inspection programs for different suppliers.

In re-cooperation deciding period, enterprise can obtain the scores and rankings of suppliers by integrating all the relevant data of suppliers, and decide whether continue cooperation or not based on the scores.

\section{Conclusion}

Aiming at the general situation of supplier management business in pumped storage enterprises, this paper constructs the supplier holographic multidimensional evaluation system, and provides a complete set of dataapplication innovative scheme of supplier management. The supplier management method of pumped storage enterprises is gradually developing towards digitalization and intelligentization. The construction of supplier holographic multidimensional evaluation system is beneficial to give full play to the digital value of enterprises, improve the operation efficiency and market competitiveness of enterprises. This research needs to be further integrated with the material supply chain management system of pumped storage companies, and iterative optimization will continue in the actual operation of the companies.

\section{Acknowledgment}

This work was supported by the State Grid Xin Yuan Company (SGXYKJ-2020-001).

\section{References}

1. Wang, J.X. (2020) Analysis and construction of nuclear power engineering equipment supplier evaluation model. L. E. M., 42: 82-85.

2. Zhang, H.Y., Lu, Y., Zhang, J., Yang, Q.Z., Zhang, Y.L. (2020) Research on supplier credit evaluation method based on big data. C. A., 39: 51-53.

3. Fan, W., Liu Y.H., Yang G.H., Tao Y. (2019) Analysis and application of supplier holographic portrait model based on big data analysis technology. E. A., 11: 7578. 
4. Wu, S.D. (2019) Research on supplier credit risk management of electric power enterprises based on big data analysis. M.I.T., 3:191-193.

5. Liu Shuai China. (2018). Research on supply chain collaboration based on big data. https://kns.cnki.net/kcms/detail/detail.aspx?FileNam $\mathrm{e}=1018164518 . \mathrm{nh} \& \mathrm{DbName}=\mathrm{CMFD} 2019$ 